\title{
SOLID STATE MORPHOLOGY AND SIZE TUNING OF NANOSTRUCTURED PLATINUM USING MACROMOLECULAR COMPLEXES
}

\author{
CARLOS DÍAZ*a, MARÍA LUISA VALENZUELA* ${ }^{* b}$, RODRIGO BAEZ ${ }^{*}$ AND MARJORIE SEGOVIA ${ }^{a}$
}

\author{
${ }^{a}$ Departamento de Química, Facultad de Ciencias, Universidad de Chile, Las Palmeras 3425, Ñuñoa, Casilla 653, Santiago, Chile. \\ ${ }^{b}$ Universidad Autónoma de Chile, Instituto de Ciencias Quimicas Aplicadas, Inorganic Chemistry and Molecular Materials Center, el Llano Subercaseaux 2801, \\ San Miguel, Santiago, Chile. \\ ${ }^{c}$ Universidad Andres Bello. Facultad de Ciencias Exactas. Doctorado en Fisicoquimica Molecular. Av. Republica 275. Santiago, Chile.
}

\begin{abstract}

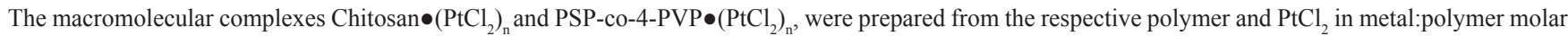
ratios 1:1 and 1:5. Pyrolisis of the macromolecular complexes Chitosan $\bullet\left(\mathrm{PtCl}_{2}\right)_{\mathrm{n}}$ and PSP-co-4-PVP• $\left(\mathrm{PtCl}_{2}\right)_{\mathrm{n}}$ at $800{ }^{\circ} \mathrm{C}$ under air affords cubic nanostructured $\mathrm{Pt}$ in the pure phase. The morphology of the pyrolityc products depends on the molar metal:polymer ratio; i.e. a "cotton" $3 \mathrm{D}$ shape for the 1:1 ratio and a "foamy" $3 \mathrm{D}$ shape for the 1:5 ratio. On the other hand, the particle size depends on the polymer nature, obtaining Pt nanoparticles as small as $6 \mathrm{~nm}$ for the chitosan precursors in both molar ratio.
\end{abstract}

Keywords: Nanoparticles, Solid State, Polymers, Plasmon.

\section{INTRODUCTION}

Platinum plays an important role in some industrial applications [1], being -for a long time- the classic catalyst . Pt acts as catalyst in hydrogenations [2], in the reduction of polluting gases expelled during the combustion of gasoline in automobiles [3], in the industrial synthesis of nitric acid (from decomposition of petroleum) [4] and in proton-exchange fuel cell [5]. All of these applications use Pt finely divided [6]. It has also been established that both, the reactivity and selectivity of nanostructures of Pt catalysis, are highly dependent on the size and morphology of the nanoparticles of Pt [7-9]. In this context, crystal planes exposed to the surface of the nanoparticles are crucial in the catalytic activity [10-13].

Thus, much research in this field has focused on new methods of manufacture Pt nanoparticles with appropriate sizes and morphologies $[14,15]$. General chemical methods of nanoparticles preparation depart from a Pt precursor, usually a salt of $\mathrm{Pt}$ (II) or $\mathrm{Pt}$ (IV) (e.g. $\mathrm{H}_{2} \mathrm{PtCl}_{4}$ or $\mathrm{H}_{2} \mathrm{PtCl}_{6}$ ) in presence of a reducer such as an alcohol, $\mathrm{NaBH}_{4}$ or $\mathrm{H}_{2}$ and polymer stabilizers (also CO or other ligand) [16-20]. The use of Pt(acac) $)_{2}$ or $\mathrm{Pt}(\mathrm{dba})_{2}$ as a metallic forerunner with various reducers and stabilizers has also been reported [21-24].

One of the most promising applications has been in cells combustion of low temperatures due to easy adsorption and dissociation of molecules of hydrogen, oxygen and various other molecules [25]. Also Nanoporous or mesoporous Platinum has been especially useful in these applications [26]. However, the methods of preparation of porous Pt are scarce.

One of the most used methods to prepare Pt nanoparticles is reducing $\mathrm{H}_{2} \mathrm{PtCl}_{4}$ or $\mathrm{H}_{2} \mathrm{PtCl}_{6}$ with $\mathrm{H}_{2}$, metallic borohidruros or alcohols in presence of polyvinylpyrrolidone as stabilizer [14, 27].

To improve the catalytic efficiency, it is common to use the Pt nanoparticles supported on a $\mathrm{SiO}_{2}$ matrix [28-30], in polymeric fibers [31, 32] carbon [33], carbon nanotubes $[34,35]$ and $\mathrm{Al}_{2} \mathrm{O}_{3}[36]$. Most of these applications require a direct solid incorporation to the solid devices. However no solid-state method to prepare Pt nanoparticles have been reported.

In this work we report a novel solid-state method for the preparation of nanostructured Pt, from the pyrolysis of macromolecular precursors PSP-co4-PVP•( $\left(\mathrm{PtCl}_{2}\right) \mathrm{n}$ and Chitosan•( $\left.\mathrm{PtCl}_{2}\right) \mathrm{n}$ 1:5 and 1:1 molar relationship [37-39].

\section{EXPERIMENTAL}

Synthesis of the macromolecular precursors

Macromolecular precursors were prepared according preious works [3739]. In a typical synthesis the respective metallic salt $\mathrm{PtCl}_{2}$ was added in a Schlenk tube over the $\mathrm{CH}_{2} \mathrm{Cl}_{2}(50 \mathrm{~mL})$ solvent under magnetic stirring and then the respective polymer PSP-co-4-PVP and Chitosan was added amount according the 1:1 and 1:5 molar ratio for 15 days at room temperature. After this the supernatant solution was extracted with a syringe and the solid dried under reduced pressure to obtain a dry solid with diverse brown colors. The molar relations indicate the initial stoichiometric relation used in the reagent and not necessarily the coordination degree of the metal in the polymeric chain.

Other details for each metallic salts reaction are given in Table 1. Subsequently, the supernatant solution was extracted with a syringe and the solid was dried under reduced pressure, see Table 1.

Table 1. Experimental details of the reactions for the formation of the precursors.

\begin{tabular}{|c|c|c|c|c|}
\hline Precursor & $\begin{array}{c}\text { Ratio } \\
\text { M/ } \\
\text { polymer }\end{array}$ & $\begin{array}{c}\text { Mass of } \\
\text { Polymer } \\
\text { (g) }\end{array}$ & $\begin{array}{c}\text { Mass of } \\
\text { metallic } \\
\text { salt (g) }\end{array}$ & $\begin{array}{c}\text { Color of the } \\
\text { product }\end{array}$ \\
\hline PSP-co-4-PVP•($\left(\mathrm{PtCl}_{2}\right)_{\mathrm{n}}$ & $\mathbf{( 1 )} 1: 1$ & 0.8222 & 0.4922 & Brown -green \\
\hline & $\mathbf{( 2 )} 1: 5$ & 2.133 & 0.4950 & Brown -green \\
\hline Chitosan $\left(\mathrm{PtCl}_{2}\right)_{\mathrm{n}}$ & $\mathbf{( 4 )} 1: 1$ & 2.4387 & 0.4997 & Brown \\
\hline & $\mathbf{( 5 )} 1: 5$ & 1.4919 & 0.5091 & Brown -green \\
\hline
\end{tabular}

Pyrolysis

The pyrolysis experiments were made by pouring a weighed portion $(0.05-0.15 \mathrm{~g})$ of the precursor 1-10 into aluminum oxide boats that were placed in a furnace (Daihan oven model Wise Therm FHP-12) under a flow of air, heating from $25^{\circ} \mathrm{C}$ to upper temperature limits of $300^{\circ} \mathrm{C}$, and then to $800^{\circ} \mathrm{C}$, followed by annealing for 2-4 $\mathrm{h}$ in each case.

\section{Characterization}

Solid pyrolytic samples were characterized by room-temperature X-ray diffraction (XRD) using a Siemens D-5000 diffractometer with $\theta-2 \theta$ geometry and the data was collected using $\mathrm{Cu}-\mathrm{K} \alpha$ radiation $(40 \mathrm{kV}$ and $30 \mathrm{~mA}$ ). Images of scanning electron microscopy (SEM) were obtained with a Philips EM 300 microscope, transmission electron microscopy (TEM) analysis was conducted on a JEOLSX100 transmission microscope and infrared spectroscopy (IR) on Perkin Elmer model spectrum BX II. The optical absorbance was measured using a UV-Visible absorption spectrophotometer Shimadzu model Shimadzu UV- 2460 equiped with an accesory for solid samples.

\section{RESULTS AND DISCUSSION}

Pt nanoparticles were obtained from the precursors Chitosan $\bullet\left(\mathrm{PtCl}_{2}\right)_{\mathrm{n}}$ and PSP-co-4-PVP• $\left(\mathrm{PtCl}_{2}\right)_{\mathrm{n}}$. See figure 1.

The characterization by $\mathrm{x}$-ray of all pyrolized samples shows typical $\mathrm{Pt}^{\circ}$ reflection planes, The typical (111), (200) and (220) planes can be indexed as indicating the presence of Pt cubic with lattice parameters comparable to that of the JCPDS card (01-087-0646) [40, 41]. Four patterns corresponding to the pyrolytic products from the precursors 1:1 and 1:5 ratio PSP-co-4-PVP $\left(\mathrm{PtCl}_{2}\right)$ ${ }_{n}$ and $1: 1$ and $1: 5$ ratio Chitosan $\bullet\left(\mathrm{PtCl}_{2}\right)_{\mathrm{n}}$ are shown in figure 2. 

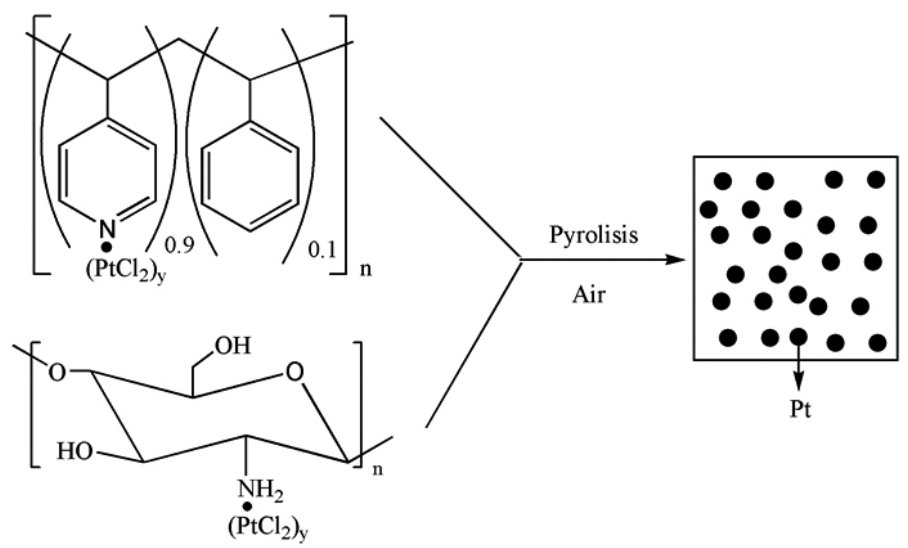

Figure. 1 Diagram of the synthesis in solid state using polymers such as molecular precursors.

(a) Pt-Qui (1:1)

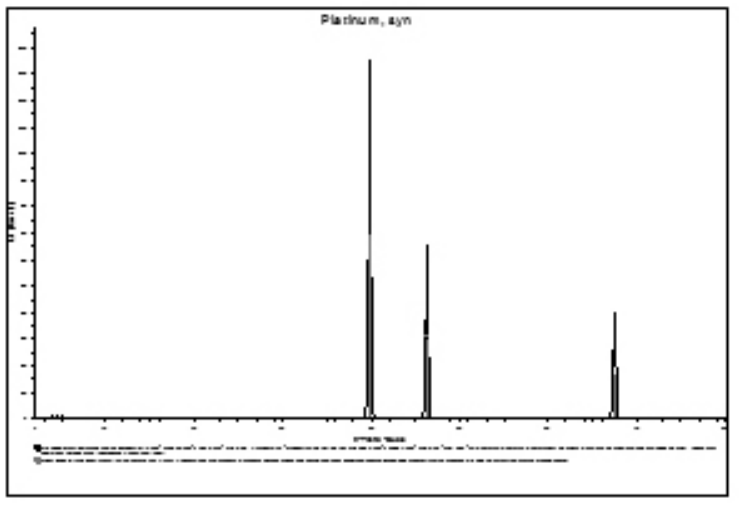

(c) Pt-PVP (1:1)

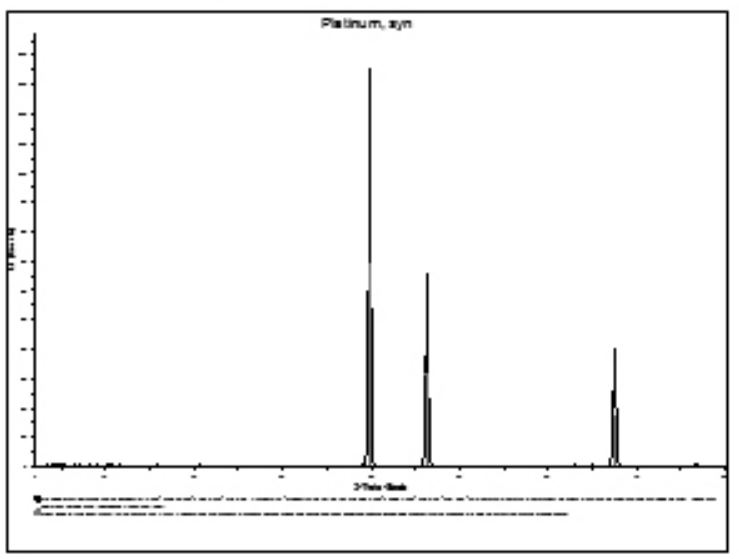

(b) Pt-Qui (1:5)

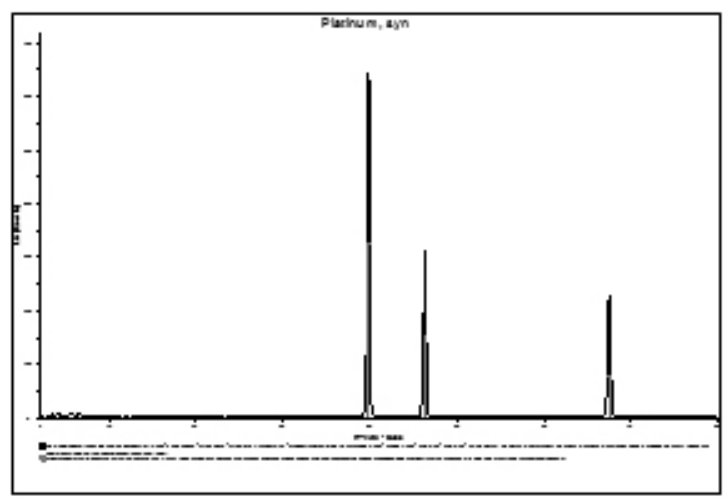

(d)

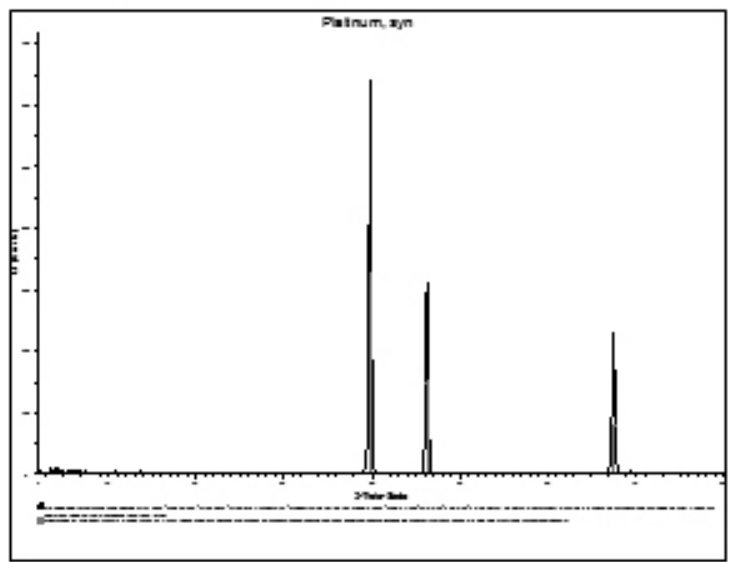

Figure. 2 XRD pattern for the pyrolytic products from Chitosan $\bullet\left(\mathrm{PtCl}_{2}\right)_{\mathrm{y}} 1: 1$ and 1:5 and PSP-co-4-PVP• $\left(\mathrm{PtCl}_{2}\right)_{\mathrm{y}} 1: 1$. The red bars correspond to the pattern of Pt Cubic (01-087-0646).

The morphology of pyrolytic products was analyzed by SEM microscopy. In general, the morphology of the product depends on the stoichiometric ratio between metal and polymer.

Figure 3 shows the foam morphology for the pyrolytic product from the precursor 1:1 and 1:5 ratio PSP-co-4-PVP• $\left(\mathrm{PtCl}_{2}\right)_{\mathrm{n}}$. This particle is one of the smallest solid-state Pt nanomaterials obtained. Another interesting aspect is the "foam like" morphology observed for pyrolytic products from the precursors 1:5 ratio PSP-co-4-PVP• $\left(\mathrm{PtCl}_{2}\right)_{\mathrm{n}}$. Few Pt metallic sponges have been reported, being this the only solid-state route for this type of materials [42]. 
(a) Pt-Qui (1:1)

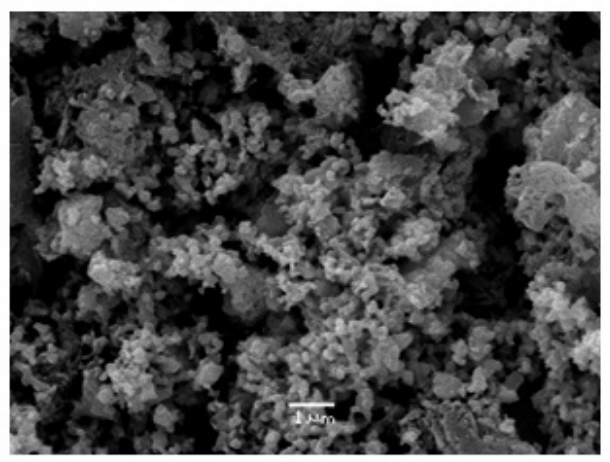

(b) Pt-Qui (1:5)

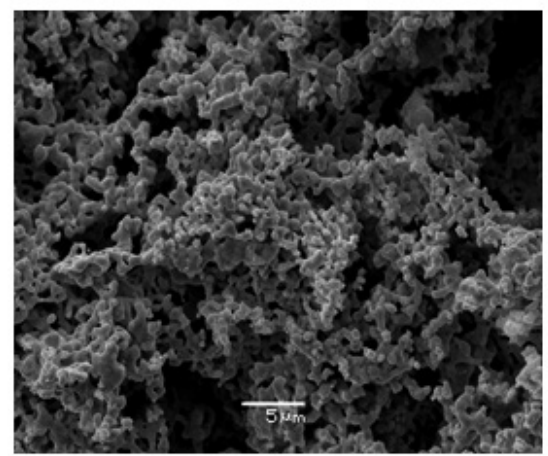

(d) Pt-PVP (1:5)

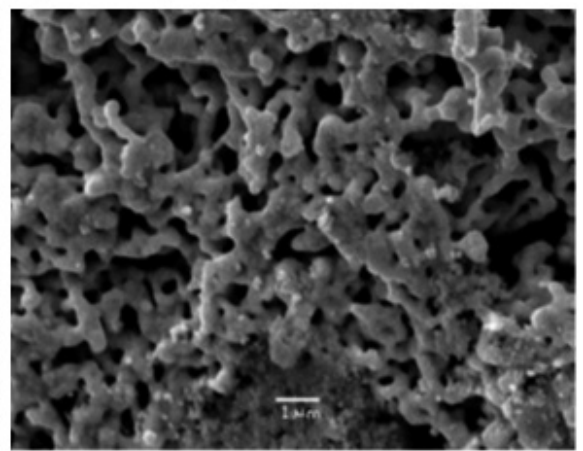

Figure. 3 SEM image for the pyrolytic products from Chitosan $\bullet\left(\mathrm{PtCl}_{2}\right)_{\mathrm{y}}$ (a) $1: 1$ and (b) 1:5 and PSPco-4-PVP• $\left(\mathrm{PtCl}_{2}\right)_{\mathrm{y}}$ (c) 1:1 and (d) 1:5.

(a) Pt-Qui (1:1)

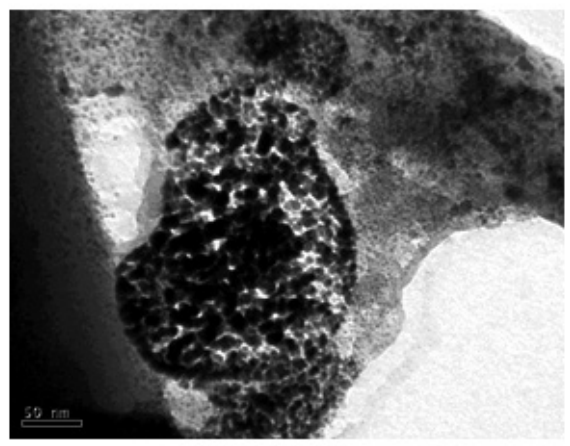

(c) Pt-PVP (1:1)

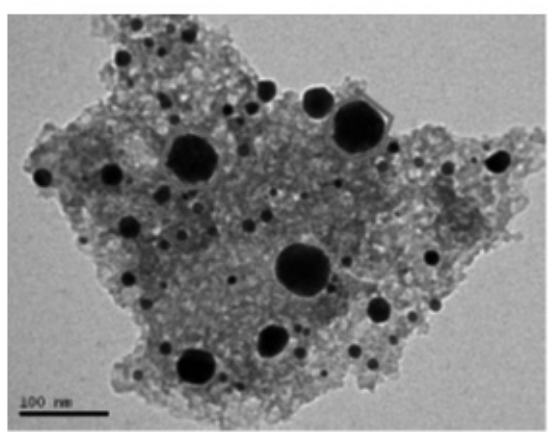

(b) Pt-Qui (1:5)

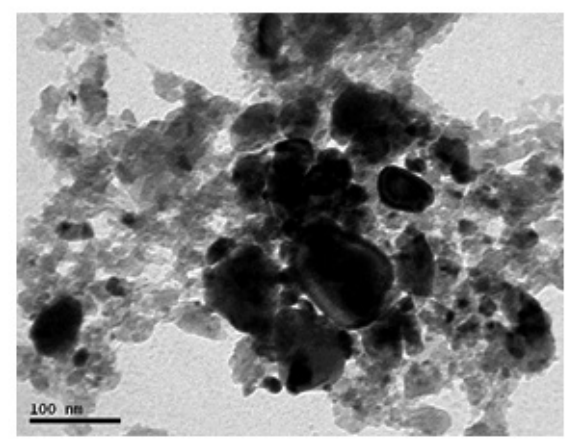

(d) Pt-PVP (1:5)

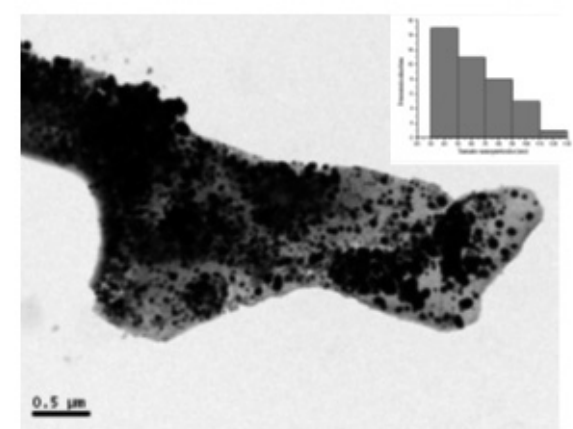

Figure 4. TEM image for the pyrolytic products from Chitosan $\bullet\left(\mathrm{PtCl}_{2}\right)_{\mathrm{y}}$ (a) $1: 1$ and (b) 1:5 and PSPco-4-PVP• $\left(\mathrm{PtCl}_{2}\right)_{\mathrm{y}}$ (c) 1:1 and (d) 1:5. 
The TEM images also exhibit a dependence of the particle size with the molar ratio of the PSP-co-4-PVP• $\left(\mathrm{PtCl}_{2}\right)$ precursors. The small size particle $(6 \mathrm{~nm})$, were obtained from the pyrolytic product from the precursors Chitosan $(\mathrm{PtCl} 2) \mathrm{n}$ in a 1:1 molar ratio. As the polymer content enhance ie. the ratio metal/polymer decrease the particle size and agglomerates increases as is shows in figure 4.

As is shown in figure 4 (c) the as obtained Pt nanoparticles exhibit varied shapes and size, some of them with the typical truncated octahedron form [43-
48]. This can be also observed as an image of a cubohedral structure viewed along the [110] zone axis.

Aditional characterization was achieved by the observation of the expected surface plasmon for the pyrolytic product of precursors PSP-co-4-PVP• $\left(\mathrm{PtCl}_{2}\right)$ and Chitosan $\bullet\left(\mathrm{PtCl}_{2}\right.$ ) in 1:1 molar ratio (see figure 5). Those exhibit a broad absoption at $293 \mathrm{~nm}$, typical of the plasmon of nanostrucured Pt [49-51].

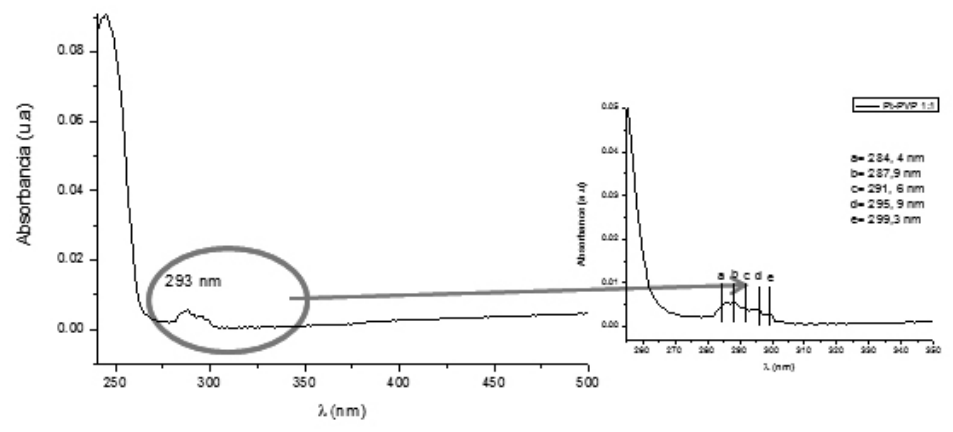

b) Chitosan $\bullet\left(\mathrm{PtCl}_{2}\right)_{\mathrm{n}}(1: 1)$

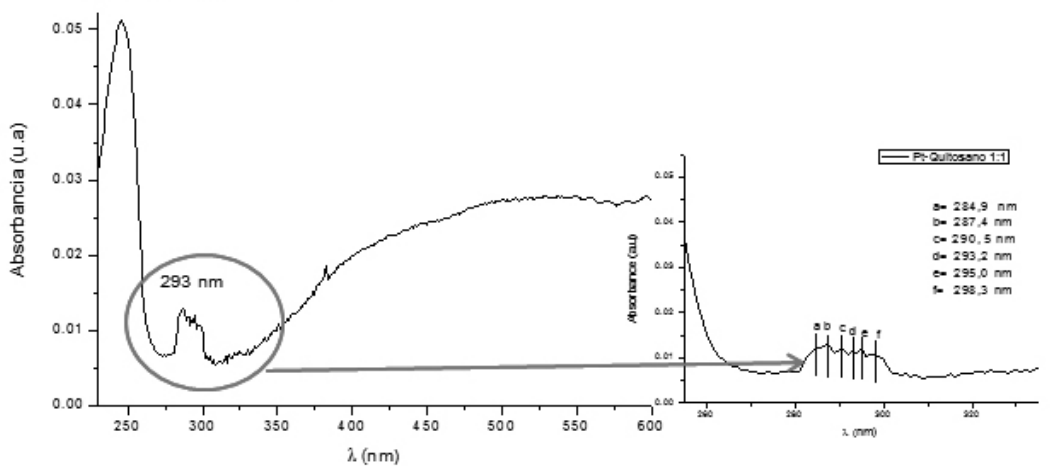

Figure 5. Uv-visible spectra of pyrolytic product from (a) PSP-co-4-PVP• $\left.\mathrm{PtCl}_{2}\right)_{\mathrm{n}}(1: 1)$,

(b) Chitosan $\bullet\left(\mathrm{PtCl}_{2}\right)_{\mathrm{n}}(1: 1)$.

On the other hand, further evidence of the structure of the Pt nanoparticles was obtained by the electron diffraction obtained from the TEM analysis, see figure 6. TEM image obtained from another side of the pyrolytic product from PSP-co-4-PVP• $\left.\mathrm{PtCl}_{2}\right)_{n}$ in molar ratio 1:1 , see fig.6a, showed an electron diffraction image, fig. $6 \mathrm{~b}$, which can be index to the typical planes of Pt with a for structure ie. the (111), (200), (200) and (311) planes [15].

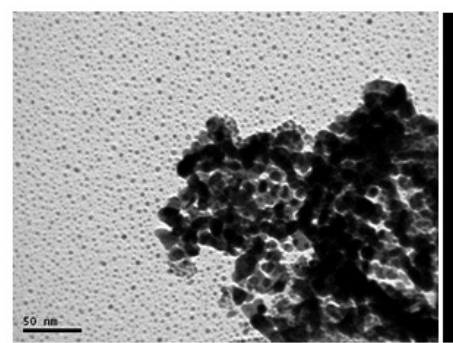

\section{(b)}

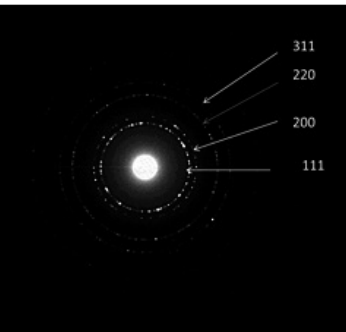

Figure 6. TEM image Pt-PVP (1:1) (a) and their electron diffraction with their main planes (b).

Although several solution preparation of $\mathrm{Pt}^{\circ}$ nanoparticles have been reported [14-27] no solid state methods for to prepare $\mathrm{Pt}^{\circ}$ nanoparticles are available. The first way, solution methods, in spite of that to allow the size and morphology control, their incorporation to a solid state device could be not easy. In solution, small nanoparticles as small as $1 \mathrm{~nm}$ have reported [8] and using the here reported solid-state method, nanoparticles of $6 \mathrm{~nm}$ have observed, although with a low dispersity, however the latter aspect is a common characteristic of the solid-state methods to prepare nanoparticles [52].

Furthermore using the here reported method some control of the morphology can be made. In fact by varying the nature of the polymer as well as the metal:polymer ratio the morphology can by choose : with precursor having the PSP-co-4-PVP and with a 1:5 ratio, $\mathrm{Pt}^{\circ}$ with a "cotton" 3D morphology was obtained while with the precursors having chitosan in 1:1 ratio metal: polymer affords most irregular shape. Also the particle size can be controlled by select both the polymer as well the metal polymer ratio from the precursor ie. the chitosan in a ratio metal polymer 1:1, afford the most small particles size.

Furthermore the here reported solid state method could permit the easy incorporation of $\mathrm{Pt}^{\circ}$ nanoparticles to solid matrix, for instance of $\mathrm{SiO}_{2}$.

\section{CONCLUSIONS}

The morphology of polymers can be controlled by the metal/polymer ratio of the precursor. For both polymers, SEM shows "metal foam" in relations 1:5 metal:polymer. Chitosan induces the formation of smaller nanoparticles $(6 \mathrm{~nm})$ for the 1:1 molar ratio than for 1:5 ratios. Unlike to the previously reported other solid state method [53-60] which start from precursor contained phosphazene derivatives linked to metal and organometallic fragments the here reported method allow the formation of phase pure metal oxides.

This method is a general alternative for the preparation of Pt nanostructured material in solid state wich could permit an ease incorporation to solid matrix for a possible practical application as microelecronic devices and solid high temperature catalyst.

In sumary the two parameters precursors, nature of the polymer and the metal: polymer ratio can tune in both the morphology and the size particle. 


\section{ACKNOWLEDGEMENT}

To Project Fondecyt 1120179 for financial support.

\section{REFERENCES}

1. F.A Cotton, G. Wilkinson, "Advanced Inorganic Chemistry", $6^{\text {ta }}$ Edicion, Wiley, New York, (1999), 1001.

2. E. Schmidt, A. Vargas, T. Mallat, and A. Baiker, J. Am. Chem. Soc. 131, 12358, (2009).

3. A. Ronxoux, J. Schulz, H. Patin, Chem. Rev. 375, 102, (2002).

4. A. T. Bell, Science. 299, 1688, (2003).

5. K.R. Williams and G.T. Catal, Today. 401, 38, (1997)

6. J. Turkevich, R.S Miner, and L. Babenkova, J.Phys. Chem. 90, 4765, (1986).

7. X. Gong, Y. Yang, L. Zhang, C. Zou, P Cai, G. Chen, and S. Huang, Journal of Colloid and Interface Science. 352, 379, (2010)

8. H. Wang, Y. Wang, Z. Zhu, A. Sapi, K. An, G. Kennedy, W. Michalak, and G. Somorjai, Nano Lett. 13, 2976, (2013).

9. Z.Y. Zhou, X. Kang, Y. Song, and S. Chen, J. Phys. Chem. C 116, 10592, (2012).

10. X. Huang, Z. Zhao, J. Fan, Y. Tan, and N. Zheng, J. Am. Chem. Soc. Rev. 133, 4718, (2011).

11. L.Y. Chang, A.S. Barnard, L. Cervera, and R.E. Dunin-Borkowski, Nano Lett. 10, 3073, (2010).

12. D. Pham Minh, Y. Oudart, B. Baubet, C. Verdon, and C. Thomazeau, Oil \& Gas Science and Technology 64, 697, (2009).

13. M. Min, C. Kim, Y. In Yang, J. Yi, and H. Lee Phys. Chem. Chem. Phys. 11, 9759, (2009).

14. J. Chen, T. Herricks, and Y. Xia, Angew. Chem. Int. 44, 2589, (2005).

15. L. Wang, M. Imura, and Y. Yamauchi, ACS Appl. Mater. Interfaces 4, 2865, (2012).

16. X. Fu, Y. Wang, N. Wu, L. Gui, and Y. Tang, Langmuir 18, 4619, (2002).

17. P. Karam, Y. Xin, S. Jaber, and L. Halaoui. J.Phys. Chem.C 112, 13846, (2008).

18. D. Fenske, H. Borchert, J. Kehres, R. Kröger, J. Parisi, and J. KolnyOlesiak, Langmuir 24, 9011, (2008).

19. J. Liu, N. Ruffini, P. Pollet, V. Llopis-Mestre, C. Dilek, C. Eckert, C. Liotta, and C. Roberts, Ind. Eng. Chem. Res. 49, 8174, (2010).

20. S.H. Chang, M.H. Yeh, C.J. Pan, K.J. Chen, H. Ishii, D.G. Liu, J.F. Lee, C.C. Liu, J. Rick, M.Y. Cheng, and B.J. Hwang, Chem. Commun. 47, 3864, (2011).

21. Y. Kang, J. Pyo, X. Ye, R. Dias, T. Gordon, E. Stach, and C. Murray, ACS Nano, 7, 645, (2013).

22. Y. Sun, M. Delucchi, and J. Ogden, International Journal Of Hydrogen Energy, 36, 11116, (2001).

23. V. Huc, K. Pelzer, Journal of Colloid and Interface Science 318, 1, (2008).

24. K. Pelzer, M. Hävecker, M. Boualleg, J.P. Candy, and J.M. Basset, Angew. Chem. 123, 5276, (2011).

25. H.T. Zhang, J. Ding, and G.M. Chow, Langmuir 24, 375, (2008).

26. X. Teng, X. Liang, S. Maksimuk, and H. Yang, Small 2, 249, (2006).

27. T. Teranishi, M. Hosoe, T. Tanaka, and M. Miyake, J. Phys. Chem., 103, 3818, (1999).

28. H. Ataee-Esfahani, Y. Nemoto, L. Wang, and Y. Yamauchi, Chem. Commun, 47, 3885, (2011).

29. U. Sanyal, S.B. Kalidindi, S. Nair, and B.R. Jagirdar, Current Science $102,78,(2012)$.

30. G. Dae Moon, and U. Jeong, Chem Mater. 20, 3003, (2008).

31. Z. Liu, S. Poyraz, Y. Liu, and X. Zhang, Nanoscale 4, 106, (2012).

32. H. Dong, and J.P. Hinestroza, ACS Appl. Mater. Interfaces 1, 797, (2009).

33. M. Chen, and Y. Xing, Langmuir 21, 9334, (2005).

34. P.L. Kuo, and C.H. Hsu, ACS Appl. Mater. Interfaces 3, 115, (2001).

35. Z. Gan, X. Zheng, D. Wei, Q. Hu, A. Zhao, X. Zhang, and G. Li, Superlattices and Microstructures 47, 705, (2010).

36. J.W. Yoo, D. Hathcock, and M.A. El-Sayed, J. Phys. Chem A 106, 2049 , (2002).

37. C. Diaz, M.L. Valenzuela V. Lavayen, K. Mendoza, O. Peña and C. O’Dwyer, Inorganica Quimica Acta. 377, 5, (2011).

38. C. Diaz, S. Platoni, A. MolinaM.L. Valenzuela, H. Geaney and C. O'Dwyer, J. Nanoscience and Nanotech. 14, 7648, (2014).

39. C. Diaz, M.L. Valenzuela, G.A.Carriedo and N. Yutronic, J.Chil.Chem. Soc. 58, 1994, (2014).
40. F. Wen, W. Zhang, G. Wei, Chem.Mater. 20, 2144, (2008)

41. P. Zheng, X.Jiang, X. Zhang, Langmuir 22, 9393, (2006).

42. B. Tappan, S. Steiner, E. Luther, Angew. Chem. Int. Ed., 49, 4544, (2010).

43. Z.L. Wang, J. Phys. Chem. B, 104, 1153, (2000).

44. H. Huang, Q. Yuan, X. Yang, Colloids and surfaces B: Biointerfaces. 39, 31, (2004).

45. P. Guo, W. Wenyan, G. Liang, J.Colloid.Interf.Sci. 323, 229, (2008).

46. C. Franco, M. Da Silva, G. Goulart, Mater.Letters., 60, 2549, (2006).

47. N. Viet Long, N. Duc Chien, T. Hayakawa, H. Hirata, G. Lakshminaraya, M. Nogami, Nanotechnology 21, 035605, (2010).

48. J. Wu, L. Qi, H. You, A. Gross, J. Li, H. Yang, J. Am. Chem. Soc., 134, 11880, (2012).

49. A. M. Garcia, M. L. Ruiz-Gonzalez, G. F. de la Fuente, P. Crespo, J. M. Gonzalez, J. Llopis, J. M.Gonzale-Clabet, M.Vallet-Regi, A.Hernaldo, Chem. Mater., 19, 889, (2007).

50. Y. Luo, Materials Letters 61, 1873, (2007)

51. A. Chen, P. Holt-Hindle, Chem. Rev. 110, 3767, (2010).

52. C. Díaz, M.L Valenzuela, in "Metallic Nanostructures Using Oligo and Polyphosphazenes as Template or Stabilizer in Solid State" in Encyclopedia of Nanoscience and Nanotechnology, H.S Nalwa Ed., American Scientific Publishers; California, 16, 239, (2010).

53. G.A. Carriedo, F.I. Fidalgo, F.J. Garcia-Alonso, A. Presa, C. Diaz and M.L. Valenzuela, Macromolecules 37, 9431, (2004).

54. C. Diaz, P. Castillo and M.L. Valenzuela, J. Cluster Science 16, 515, (2005).

55. C. Diaz and M.L. Valenzuela, J. Inorg. Organomet. Pol. 16, 41, (2006).

56. C. Diaz, M.L. Valenzuela, E. Spodine, Y. Moreno, O. Peña, J. Cluster Science 18, 831. (2007).

57. C. Diaz, M.L. Valenzuela, S. Ushak, J. Cluster Science 19, 471, (2008).

58. C. Diaz, M.L. Valenzuela, D. Bravo, V. Lavayen, C. O'Dwyer, Inorg. Chem. 47, 11561, (2008)

59. C. Diaz, M.L. Valenzuela, L. Zuñiga, C. O’Dwyer, J. Inorg. Organomet. Pol. 19, 507, (2009).

60. C. Diaz, M.L. Valenzuela, V. Villalobos, N. Yutronic, J. Cluster Science 22, 963, (2011) 